\title{
Radical Hysterectomy with Pelvic Lymphadenectomy: Indications, Technique, and Complications
}

\author{
Rachel A. Ware and John R. van Nagell Jr. \\ Division of Gynecologic Oncology, Department of Obstetrics and Gynecology, The University of Kentucky Chandler Medical Center \\ and Markey Cancer Center, 800 Rose Street, Lexington, KY 40536-0293, USA \\ Correspondence should be addressed to John R.van Nagell Jr., jrvann2@email.uky.edu
}

Received 9 December 2009; Accepted 11 June 2010

Academic Editor: Liselotte Mettler

Copyright ( 2010 R. A. Ware and J. R. van Nagell Jr. This is an open access article distributed under the Creative Commons Attribution License, which permits unrestricted use, distribution, and reproduction in any medium, provided the original work is properly cited.

Radical hysterectomy with pelvic lymphadenectomy remains the treatment of choice for women with Stages $\mathrm{IA}_{2}$ and $\mathrm{IB}_{1}$ carcinoma of the cervix, and selected patients with Stage II endometrial cancer. Improvement in surgical techniqe, administration of prophylactic antibiotics, thromboemolic prophylaxis, and advances in critical care medicine have resulted in lower operative morbidity associated with this procedure. Major urinary tract complications such as ureteral injury or vesico-vaginal fistula are now extremely rare $(<1 \%)$. Five-year survival rates following this procedure vary according to a number of clinical and histologic variables, and may be as high as $90 \%$ in women without lymph node metastases.

\section{Introduction}

The number of patients with early stage cervical cancer has steadily increased with the widespread use of the Papanicolaou test for screening. In 2009, it is estimated that there will be 11,070 new cases of cervical cancer in the United States and nearly 500,000 new cases worldwide. Approximately $85 \%$ of newly diagnosed cervical cancer in industrialized countries are expected to have localized or regional disease $[1,2]$. With the trend toward early detection, more patients with invasive cervical cancer are diagnosed with early stage disease and are candidates for primary surgical treatment with radical hysterectomy and pelvic lymphadenectomy.

In 1898, Ernst Wertheim of Vienna described the operation of radical hysterectomy including removal of the parametrium and pelvic lymph nodes. In 1905, Wertheim reported outcomes of the first 270 patients treated by radical hysterectomy, which included an operative mortality rate of $18 \%$ and a major morbidity rate of $31 \%$. Since that time, radical hysterectomy with pelvic lymphadenectomy has been performed with modifications in surgical technique as the major surgical treatment for early stage invasive cervical cancer $[3,4]$. The use of prophylactic antibiotics, thromboembolic prophylaxis, administration of blood products, and advances in postoperative and critical care medicine all have lowered operative morbidity, and increased the survival rate of cervical cancer patients treated with this operation.

\section{Indications}

The primary indication for radical hysterectomy with pelvic lymphadenectomy is Stage I invasive cervical cancer. Early invasive cervical cancer is divided by the International Federation of Gynecology and Obstetrics (FIGO) Staging System into Stage $\mathrm{IA}_{1}$, which includes lesions invading the cervical stroma to a depth of $3 \mathrm{~mm}$, or less and a maximum horizontal spread of $7 \mathrm{~mm}$, and Stage $\mathrm{IA}_{2}$, which includes lesions with stromal invasion of $3-5 \mathrm{~mm}$ and a maximum horizontal spread of $7 \mathrm{~mm}$ [5]. These diagnoses can be made only after careful histologic evaluation of a conization specimen using an ocular micrometer to establish the depth of stromal invasion. Patients with Stage $\mathrm{IB}_{1}$ cervical cancer have microscopic evidence of stromal invasion $>5 \mathrm{~mm}$, horizontal spread $>7 \mathrm{~mm}$ or a clinically visible cervical lesion $\leq 4.0 \mathrm{~cm}$ diameter. In patients with FIGO Stage IA $_{1}$ cervical cancer and no evidence of lymph vascular space invasion (LVSI), conservative therapy with cervical conization or simple 


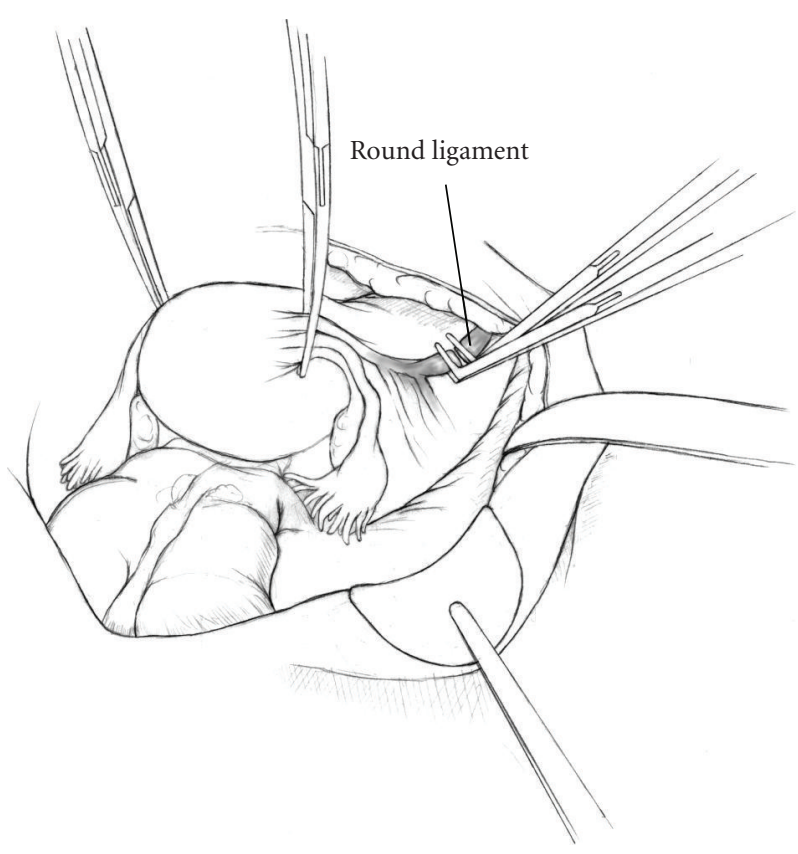

FIGURE 1

hysterectomy is appropriate [6-11]. However, patients with Stage $\mathrm{IA}_{2}$ or Stage $\mathrm{IB}_{1}$ cervical cancer have a significant risk of lymph nodal spread and should be treated by radical hysterectomy and pelvic lymphadenectomy. Patients with Stage $\mathrm{IB}_{2}$ or Stage IIA cervical cancer are treated with chemoradiation or combined therapy in many institutions. However, selected patients with Stage $\mathrm{IB}_{2}$ or IIA cervical cancer may be treated with radical hysterectomy and pelvic lymphadenectomy [12-14].

Radical hysterectomy may also be considered in the treatment recurrent cervical cancer. This procedure is appropriate only in patients with small central recurrences, following primary radiation of early stage disease. Maneo and colleagues, for example reported that radical hysterectomy is a safe alternative to pelvic exenteration in patients with Stage IB/IIA cervical cancer treated by primary radiation therapy, who have a recurrence $<4 \mathrm{~cm}$ in diameter without evidence of ureteral obstruction or parametrial involvement [15].

Finally, radical hysterectomy with pelvic lymphadenectomy is indicated in patients with endometrial cancer and endocervical involvement (FIGO Stage II disease). Boente reviewed the clinical, surgical, and histopathologic data from 202 patients with endometrial adenocarcinoma and cervical involvement, and reported a survival advantage for patients treated by radical hysterectomy with pelvic lymphadenectomy when compared to total abdominal hysterectomy. This advantage was most notable in patients with multiple high-risk factors [16]. Radical hysterectomy with pelvic lymphadenectomy alone can be therapeutic in selected patients with Stage II endometrial cancer, thereby avoiding the morbidity associated with combination therapy [17].

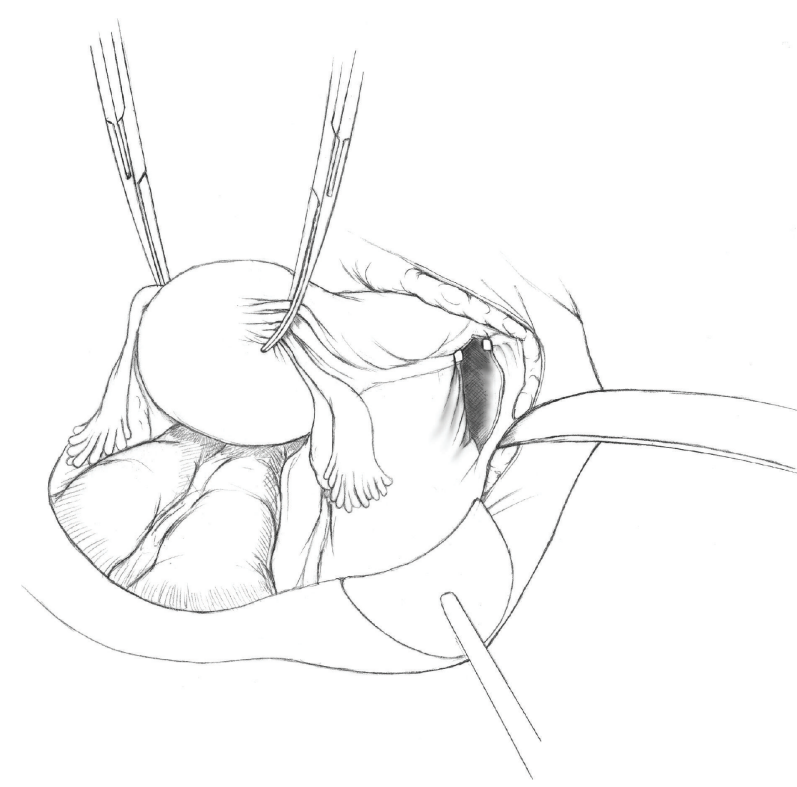

FIGURE 2

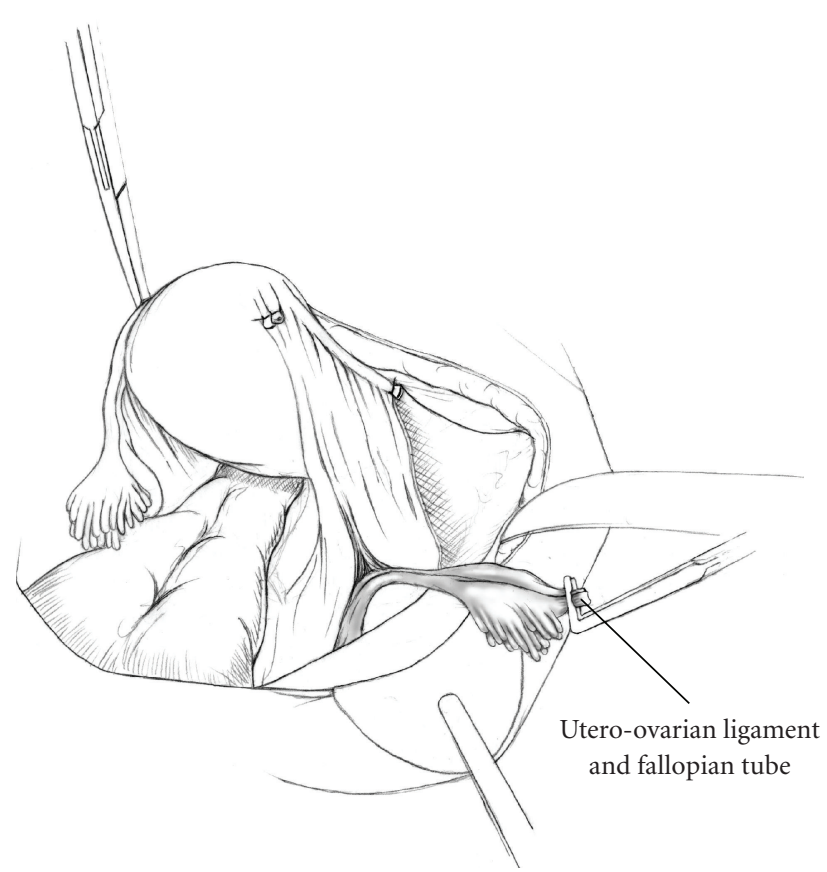

FIgURe 3

\section{Preoperative Evaluation}

Prior to undergoing radical hysterectomy, patients should have a thorough evaluation to insure that there are no major medical contraindications to surgery. The anesthesiologist should be aware of the potential for blood loss in patients undergoing this procedure and should make preparation for central venous access as well as the availability of properly typed and cross-matched blood. A prophylactic antibiotic, usually a first generation cephalosporin, is given within 30 minutes of skin incision [18]. Heparin 5000 units is given 


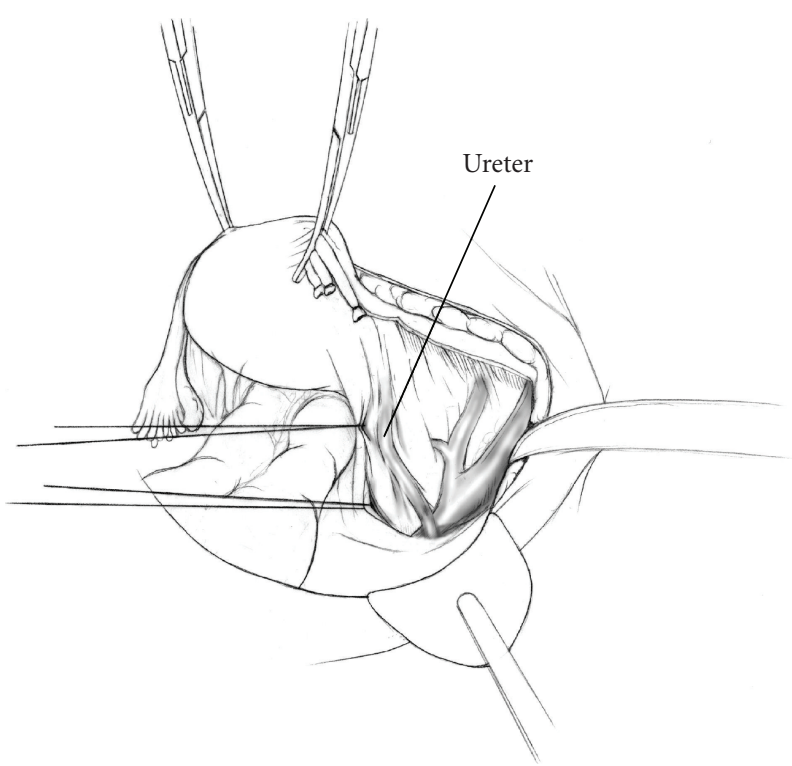

Figure 4

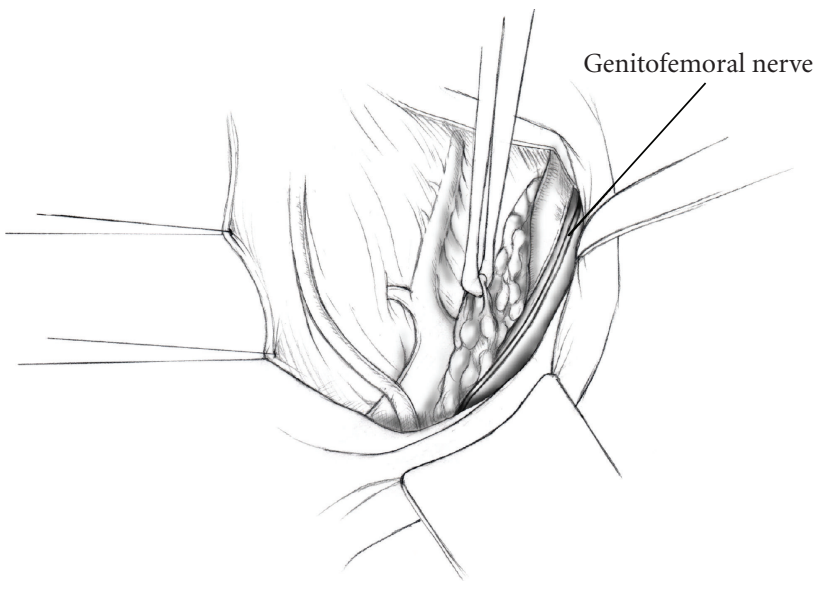

Figure 5

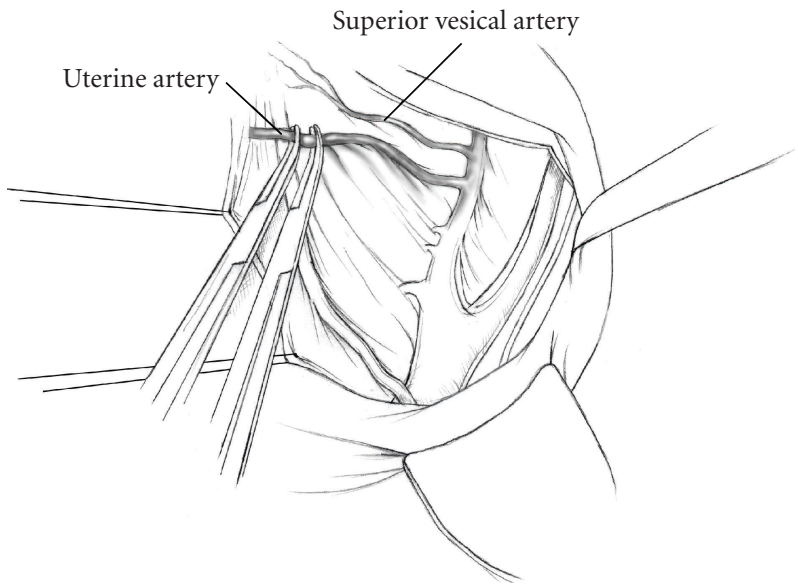

Figure 6

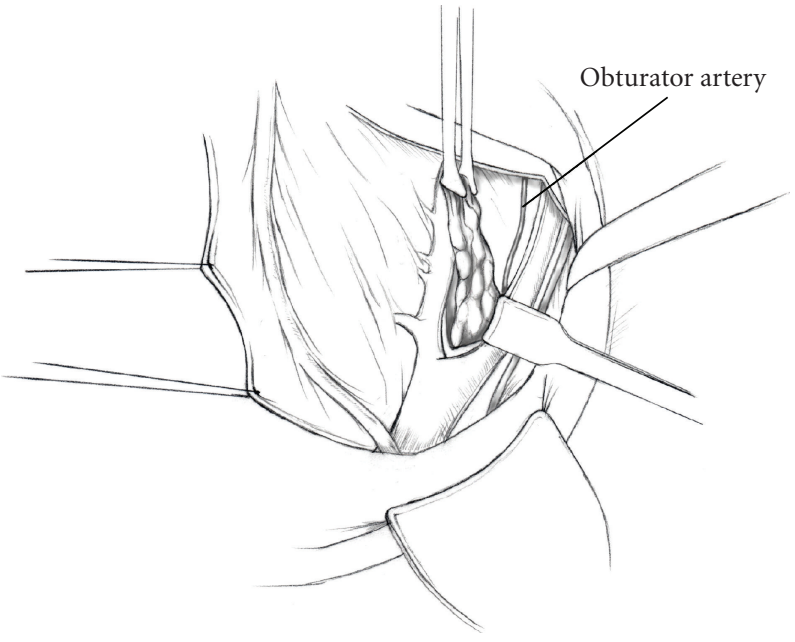

Figure 7

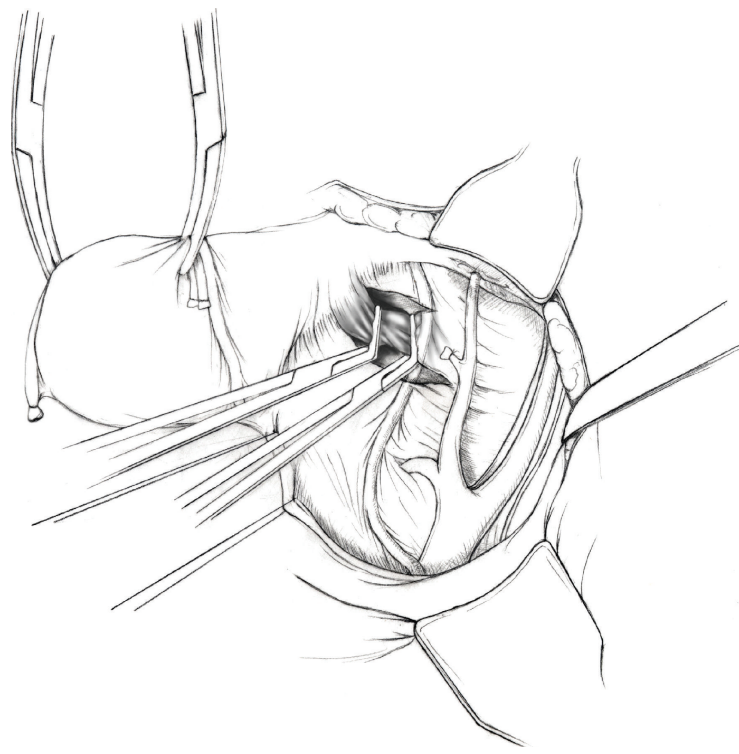

Figure 8

subcutaneously prior to surgery and three times daily in the postoperative period for thromboembolic prophylaxis. In addition, sequential compression devices (SCDs) are placed on both lower extremities immediately prior to surgery, and are left in place until the patient is ambulating [19].

\section{Surgical Technique}

(1) The patient is placed in supine position and the abdomen and vagina are prepped. A foley catheter is placed in the patient's bladder, and SCD's are placed on both lower extremities.

(2) A vertical midline incision is made $3 \mathrm{~cm}$ above the umbilicus and is extended inferiorly to the pubic symphysis. A Bookwalter retractor is placed, and 


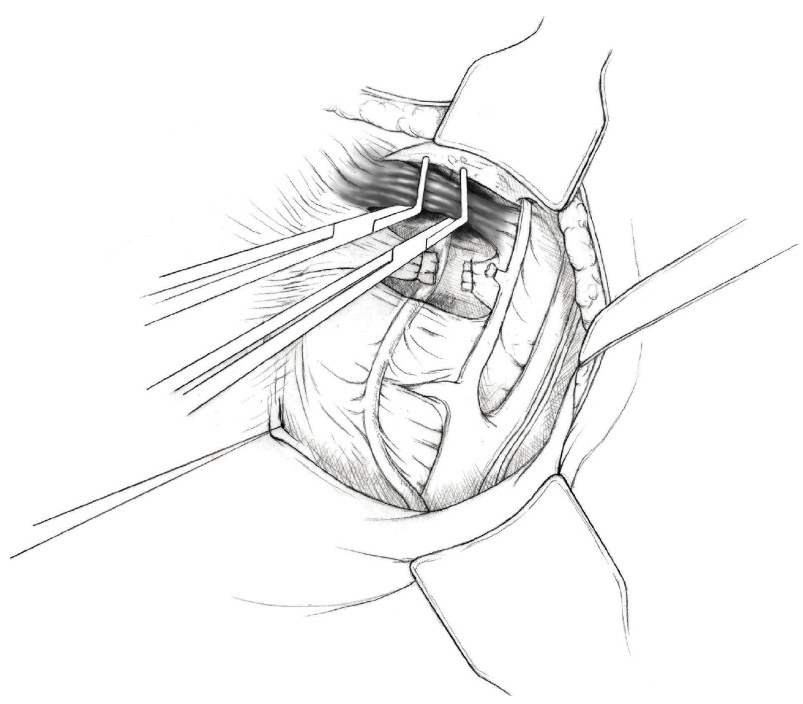

Figure 9

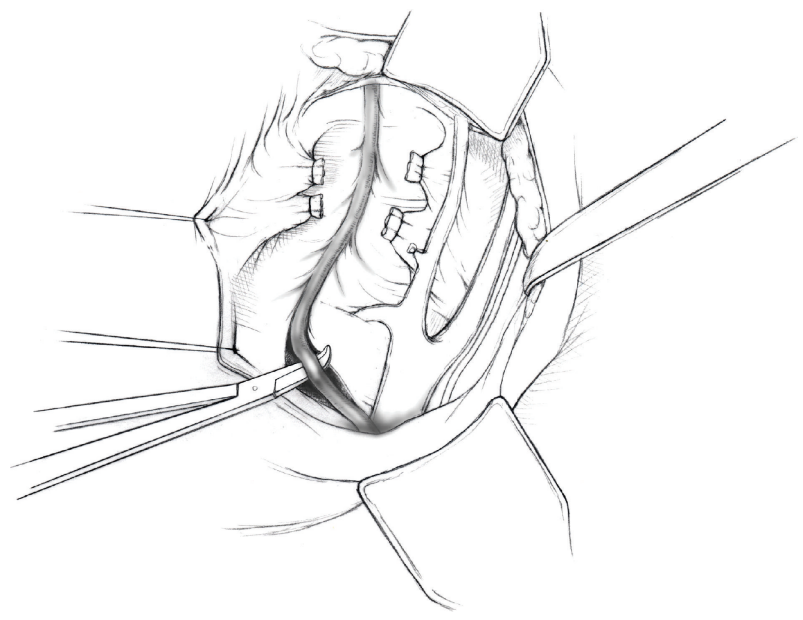

FIgURe 10

right-angle or body wall retractors are used to retract the pelvic sidewalls.

(3) Prior to initiating the pelvic procedure, the entire abdominal cavity is evaluated for evidence of metastatic disease. This includes all surfaces of the liver and diaphragm, the celiac plexus, omentum, small, and large bowel surfaces as well as the mesentery. Pelvic and para-aortic lymph nodes are palpated, and any enlarged or suspicious nodes are excised and sent for histologic evaluation.

(4) The bowel is packed into the upper abdomen using warm, moist laparotomy sponges. Two 8-inch Kelly Clamps are placed on the uterine cornua for retraction.

(5) The right round ligament is clamped, cut, and ligated at the right lateral pelvic wall (Figure 1). The anterior leaf of the right broad ligament is incised inferiorly along the lateral pelvic wall for a distance of approximately $3 \mathrm{~cm}$.

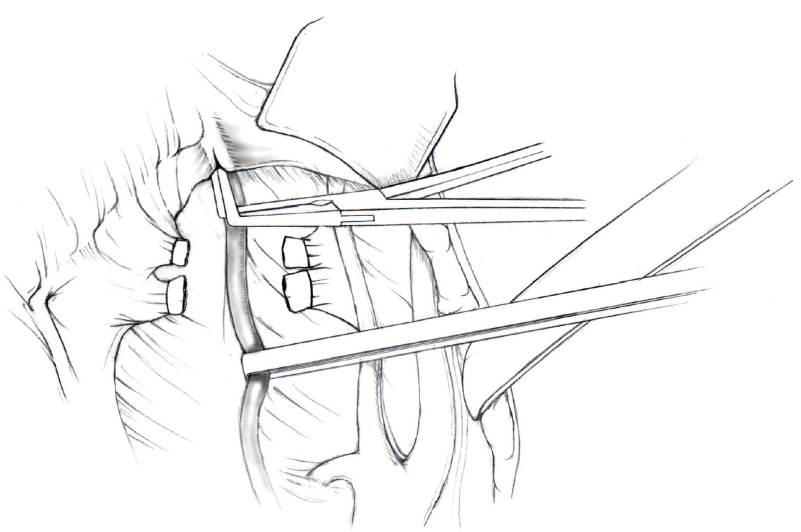

Figure 11

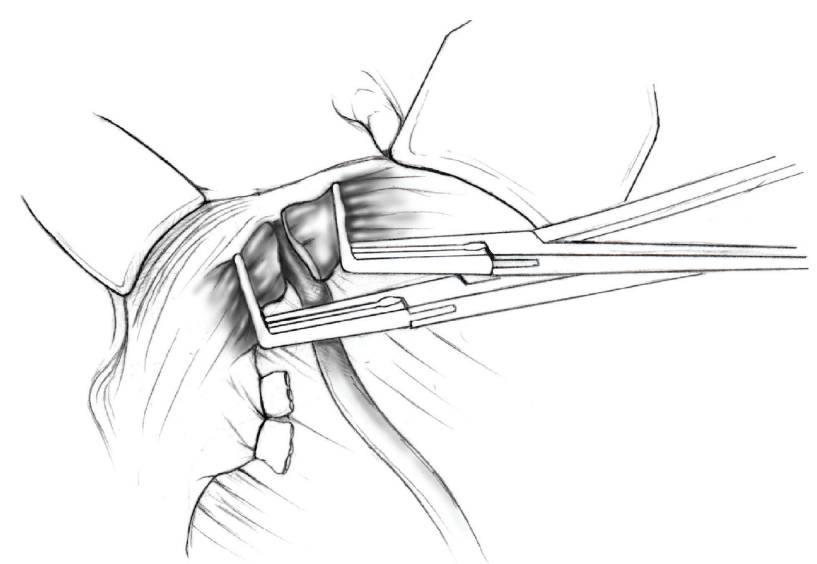

Figure 12

(6) The posterior leaf of the right broad ligament is incised superiorly along the lateral pelvic wall to the level of the infundibulopelvic ligament (Figure 2).

(7) If the right ovary is to be preserved, the posterior leaf of the right broad ligament is further incised parallel and inferior to the infundibulopelvic and uteroovarian ligaments. The right utero-ovarian ligament is then clamped, cut, and ligated, and the ovary is placed in the right iliac fossa (Figure 3).

(8) If the right ovary is to be excised, the right infundibulopelvic ligament is clamped, cut, and doubly ligated at the lateral pelvic wall. The right utero-ovarian ligament is then clamped, cut, and suture ligated, and the right tube and ovary are removed.

(9) Steps (5)-(8) are then repeated on the left side.

(10) The right retroperitoneal space is entered along the lateral pelvic wall, thereby exposing the common iliac, external iliac, and internal iliac arteries and associated lymph nodal tissue.

(11) The ureter is identified, and two silk sutures are placed in the adjacent medial peritoneum, thereby pulling the ureter medially away from the iliac vessels (Figure 4). 


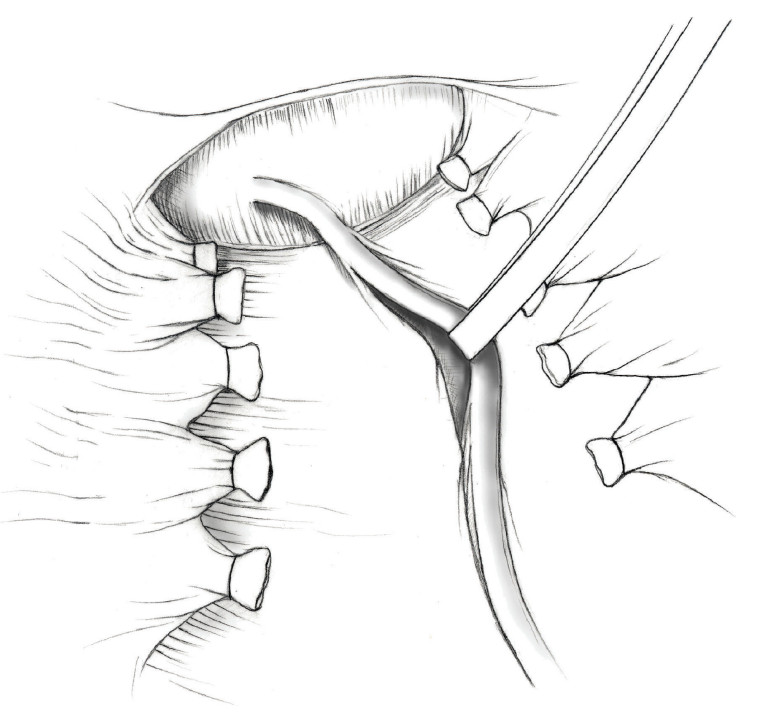

FIGURE 13

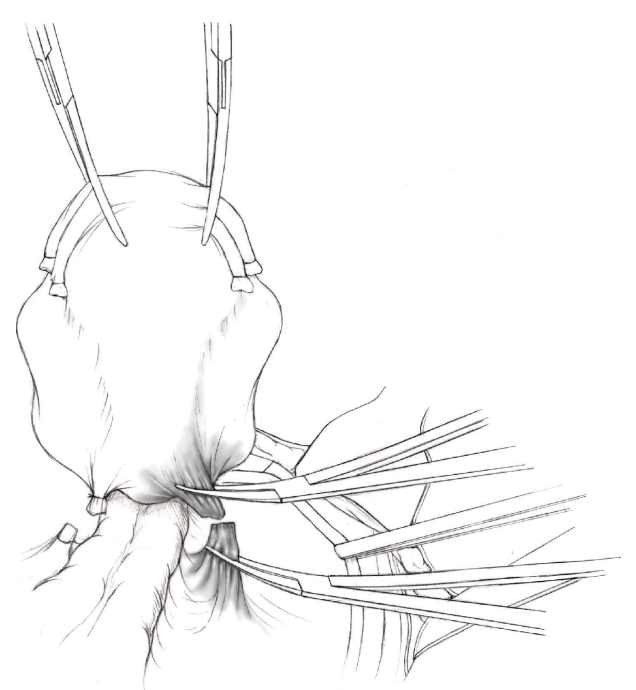

FIGURE 14

(12) The lymph node dissection is begun by sharply excising all lymph nodal tissue surrounding the right common iliac, external iliac, and internal iliac arteries. The lateral extent of the pelvic lymph node dissection is defined by the genitofemoral nerve (Figure 5). The external iliac and common iliac arteries are retracted laterally, and lymph nodal tissue surrounding the common iliac, external iliac, and internal iliac veins is removed by sharp dissection. Lymph nodal tissue from each of the major anatomic sites (i.e., common iliac, external iliac, internal iliac) is placed in separate containers and submitted for histologic analysis.

(13) The anterior division of the internal iliac artery is identified, and the uterine artery is isolated, ligated with 2-0 silk ties, and transected. The superior vesical artery is preserved (Figure 6).

(14) A vein retractor is placed on the medial aspect of the external iliac artery and vein, and the obturator nerve is identified. All lymph nodal tissue is removed from the obturator fossa by sharp dissection (Figure 7), placed in a separate container and submitted for histologic analysis.

(15) Steps (10)-(14) are repeated on the left side.

(16) The right pararectal space and paravesical spaces are defined by blunt dissection, and the lateral aspect of the cardinal ligament containing the vascular web is clamped, cut, and ligated with 2-0 silk ties (Figures 8 and 9). Ligation of the left vascular web is completed in the same fashion.

(17) The right ureter is dissected from the medial peritoneum at the level of the uterosacral ligament (Figure 10), and a $3 / 8$ inch Penrose drain is placed around the ureter (Figure 11). The ureter is dissected laterally from the parametrial tunnel using right angle clamps (Figure 12). The parametrial vasculature is ligated, and the ureter is rolled laterally out of the tunnel. The right ureter is dissected free from surrounding tissue until its entrance into the bladder (Figure 13). The left ureter is then dissected free from the left parametrium in the same fashion.

(18) The bladder is sharply dissected from the anterior vagina, and the peritoneum between the uterus and the rectum is incised. The anterior rectal wall is reflected away from the posterior vagina.

(19) The uterus is elevated and the uterosacral ligaments are clamped, cut, and tied (Figure 14). The anterior, posterior, and lateral attachments of the uterus and parametria have now been ligated. The paravaginal tissue at the inferior margin of the dissection is clamped, cut, and tied using curved Lainz clamps (Figure 15).

(20) The vagina is transected approximately $3 \mathrm{~cm}$ below the cervix and isolated bleeding sites on the vaginal cuff are ligated using 2-0 vicryl suture. The vagina is closed using a continuous interlocking 0 vicryl suture (Figure 16).

(21) Closed suction drains may be placed in both retroperitoneal spaces at the discretion of the surgeon. These drains are brought out through the anterior abdominal wall in each lower quadrant and are sutured to the skin using 2-0 silk suture.

(22) If the ovaries are retained, they are suspended to the lateral pelvic wall with 2-0 prolene, and titanium clips are placed on the suture site for future identification.

(23) The abdomen is then closed in layers, using continuous 0 looped PDS in a modified Smead-Jones technique. 


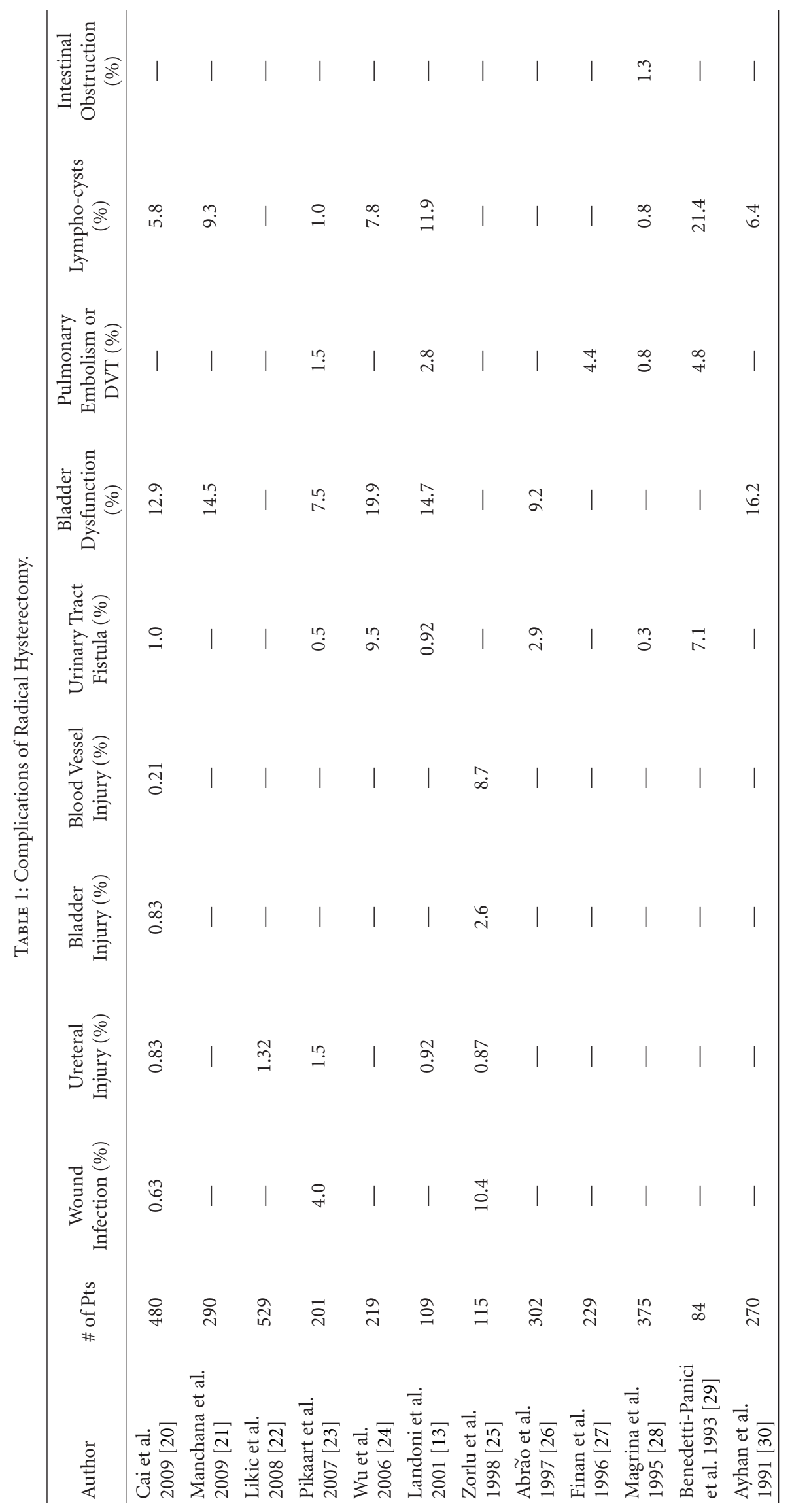


TABLE 2: Five-year survival following radical hysterectomy for cervical cancer.

\begin{tabular}{|c|c|c|c|c|c|c|c|c|}
\hline Author & \# of Pts & Stage & $\begin{array}{l}\text { Size of } \\
\text { Lesion } \\
(\mathrm{cm})\end{array}$ & $\begin{array}{l}\text { Depth of } \\
\text { Stromal } \\
\text { Invasion }\end{array}$ & $\begin{array}{l}\text { Lymphvascular } \\
\text { Space Invasion }\end{array}$ & $\begin{array}{l}\text { Lymph Node } \\
\text { Status }\end{array}$ & $\begin{array}{c}5 \text {-Year } \\
\text { Survival (\%) }\end{array}$ & $P$ value \\
\hline \multirow[t]{3}{*}{$\begin{array}{l}\text { Sartori et al. } \\
2007 \text { [31] }\end{array}$} & 454 & IB-IIA & - & - & - & All & 80 & $<.01$ \\
\hline & & & & & & Negative & 88 & \\
\hline & & & & & & Positive & 57 & \\
\hline \multirow[t]{7}{*}{$\begin{array}{l}\text { Ho et al. } \\
2004 \text { [32] }\end{array}$} & 197 & IB-II & - & All & - & - & 82 & \\
\hline & & & & Inner $2 / 3$ & - & - & 88.8 & .003 \\
\hline & & & & Outer $1 / 3$ & - & - & 73.8 & \\
\hline & & & & & Negative & - & 89.5 & $<.001$ \\
\hline & & & & & Positive & - & 68.4 & \\
\hline & & & & & & Negative & 87.3 & $<.001$ \\
\hline & & & & & & Positive & 67.2 & \\
\hline \multirow[t]{5}{*}{$\begin{array}{l}\text { Ayhan et al. } \\
2004 \text { [33] }\end{array}$} & 393 & IB & All & - & - & - & 91 & \\
\hline & & & $\leq 4$ & - & - & - & 91.0 & .012 \\
\hline & & & $>4$ & - & - & - & 85.9 & \\
\hline & & & & - & Negative & - & 93.7 & .009 \\
\hline & & & & - & Positive & - & 86.0 & \\
\hline $\begin{array}{l}\text { Landoni et al. } \\
2001[13]\end{array}$ & 238 & IB-IIA & All & - & - & - & 79 & \\
\hline \multirow[t]{5}{*}{$\begin{array}{l}\text { Tsai et al. } \\
1999 \text { [12] }\end{array}$} & 222 & IB-IIA & All & - & - & - & 76 & \\
\hline & & & $\leq 4$ & - & - & - & 88 & .0003 \\
\hline & & & $>4$ & - & - & - & 67 & \\
\hline & & & & & & Negative & 87 & .0011 \\
\hline & & & & & & Positive & 71 & \\
\hline \multirow[t]{9}{*}{$\begin{array}{l}\text { Lai et al. } \\
1999 \text { [34] }\end{array}$} & 827 & IB-II & $<2$ & - & - & - & 90.6 & .0001 \\
\hline & & & $2-4$ & - & - & - & 82.7 & \\
\hline & & & $>4$ & - & - & - & 69.1 & \\
\hline & & & & Inner $2 / 3$ & - & - & 90.3 & .0001 \\
\hline & & & & Outer $1 / 3$ & - & - & 74.9 & \\
\hline & & & & & Negative & - & 86.3 & .0002 \\
\hline & & & & & Positive & - & 76.5 & \\
\hline & & & & & & Negative & 87.3 & .0001 \\
\hline & & & & & & Positive & 68.2 & \\
\hline
\end{tabular}

\section{Complications}

Complications of radical hysterectomy with pelvic lymphadenectomy are summarized in Table 1. Bladder dysfunction and lymphocyst formation are among the most common complications of radical hysterectomy and occur in $5 \%-15 \%$ of cases in recent reports. Bladder dysfunction results from extensive dissection of the ureters at the bladder base and transection of the uterosacral ligaments, which interrupts autonomic nerve supply to the bladder. In general, more radical dissection results in a higher frequency of bladder dysfunction. However, preservation of the superior vesical artery and blood supply to the distal ureter has resulted in a marked decrease in the frequency of vesicovaginal and ureterovaginal fistula following radical hysterectomy.

Lymphocyst formation after radical hysterectomy and lymphadenectomy is due to interruption of efferent pelvic lymphatics and can result in lymphedema, pelvic discomfort, and infection as well as an increase in the frequency of deep venous thrombosis and pulmonary embolism. Variation in the incidence of lymphocyst formation depends on the extent of lymphadenectomy, retroperitoneal drain 


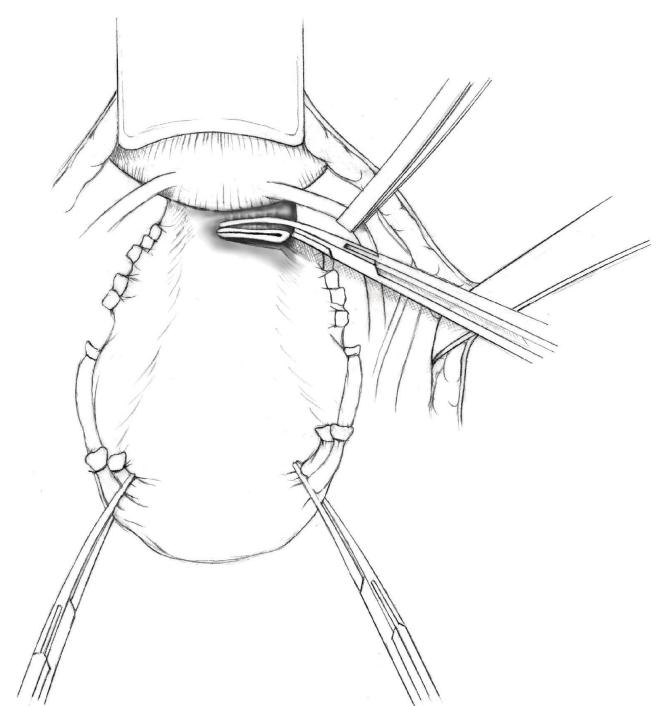

Figure 15

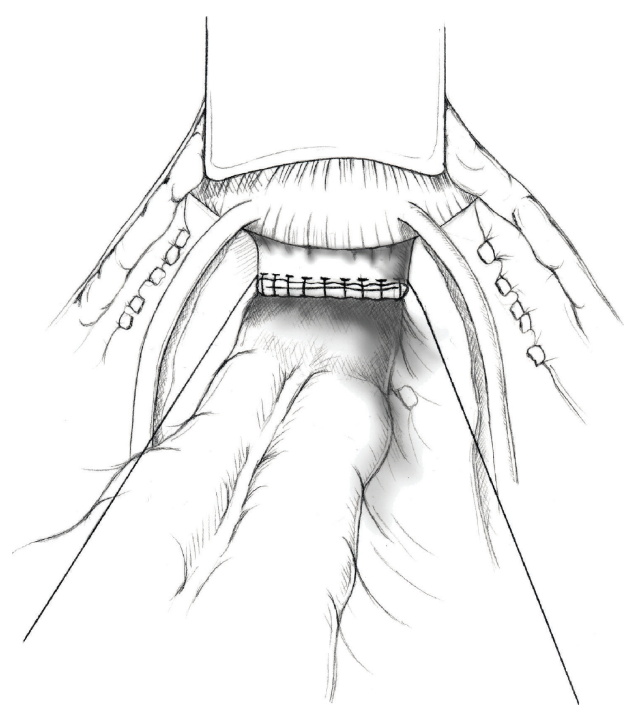

FIgURe 16

placement, and differences in the surgical technique used for ligating lymphatic channels. Lymphocysts can be managed with guided-percutaneous drainage or laparoscopic surgical resection $[35,36]$.

The incidence of thromboembolic disease after radical hysterectomy has decreased over time, as a result of widespread implementation of thromboprophylaxis with preoperative and postoperative Heparin and lower extremity sequential compression devices. Nevertheless, it remains the leading cause of mortality in the immediate postoperative period. Multiple clinical trials have provided irrefutable evidence that thromboprophylaxis decreases the risk of deep venous thrombosis and pulmonary embolus. Pulmonary embolus has been cited as the most common cause of preventable hospital death, therefore making thromboprophylaxis the number one strategy to improve safety for patients undergoing major pelvic surgery [19].

\section{Survival}

The 5-year survival in patients with early stage cervical cancer treated with radical hysterectomy and pelvic lymphadenectomy varies between $80 \%$ and 95\% according to a number of clinical and histologic findings, and is summarized in Table 2. Patients with low-risk early-stage disease, undergoing radical surgical treatment have a survival of nearly $100 \%$ [20]. However, patients with more advanced disease have lower reported outcomes. Several risk factors related to poor prognosis include large tumor volume, deep stromal invasion, presence of lymph vascular space invasion, and lymph node metastases [31-33]. A thorough analysis of these factors is helpful in determining which patients may benefit from postoperative therapy following radical hysterectomy.

\section{Summary}

Radical hysterectomy with pelvic lymphadenectomy is the treatment of choice for healthy women with stage $\mathrm{IA}_{2}$ $\mathrm{IB}_{1}$ cervical carcinoma. Women with nonbulky $\mathrm{IB}_{2}$ and IIA cervical carcinoma, centrally recurrent disease, and endometrial carcinoma with cervical involvement may also be considered for surgical treatment by radical hysterectomy. Improvements in surgical technique, prophylactic antibiotics, thromboembolic prophylaxis, administration of blood products, and advances in postoperative and critical care medicine all have lowered operative morbidity from this procedure. Five-year survival rates in excess of $90 \%$ can be achieved when this procedure is performed for the proper indications.

\section{References}

[1] A. Jemal, R. Siegel, E. Ward, Y. Hao, J. Xu, and M. J. Thun, "Cancer statistics, 2009," CA: Cancer Journal for Clinicians, vol. 59, no. 4, pp. 225-249, 2009.

[2] R. Sankaranarayanan, "Overview of cervical cancer in the developing world. FIGO 6th Annual Report on the Results of Treatment in Gynecological Cancer," International Journal of Gynecology and Obstetrics, vol. 95, supplement 1, pp. S205S210, 2006.

[3] H. Okabayashi, "Radical abdominal hysterectomy for cancer of the cervix uteri, modification of the Takayama operation," Surgery, Gynecology \& Obstetrics, vol. 33, pp. 335-341, 1921.

[4] M. S. Piver, F. Rutledge, and J. P. Smith, "Five classes of extended hysterectomy for women with cervical cancer," Obstetrics and Gynecology, vol. 44, no. 2, pp. 265-272, 1974.

[5] S. Pecorelli, "Revised FIGO staging for carcinoma of the vulva, cervix, and endometrium," International Journal of Gynaecology and Obstetrics, vol. 105, no. 2, pp. 103-104, 2009.

[6] M. Itsukaichi, H. Kurata, M. Matsushita et al., "Stage Ia1 cervical squamous cell carcinoma: conservative management after laser conization with positive margins," Gynecologic Oncology, vol. 90, no. 2, pp. 387-389, 2003.

[7] C.-J. Tseng, S.-G. Horng, Y.-K. Soong, S. Hsueh, G.-H. Hsieh, and H.-W. Lin, "Conservative conization for microinvasive carcinoma of the cervix," American Journal of Obstetrics and Gynecology, vol. 176, no. 5, pp. 1009-1010, 1997. 
[8] C. Orlandi, S. Costa, P. Terzano et al., "Presurgical assessment and therapy of microinvasive carcinoma of the cervix," Gynecologic Oncology, vol. 59, no. 2, pp. 255-260, 1995.

[9] M. Ueki, "Conservative therapy for microinvasive carcinoma of the uterine cervix," Gynecologic Oncology, vol. 53, no. 1, pp. 109-113, 1994.

[10] M. Morris, M. F. Mitchell, E. G. Silva, L. J. Copeland, and D. M. Gershenson, "Cervical conization as definitive therapy for early invasive squamous carcinoma of the cervix," Gynecologic Oncology, vol. 51, no. 2, pp. 193-196, 1993.

[11] B.-U. Sevin, M. Nadji, H. E. Averette, S. Hilsenbeck, D. Smith, and B. Lampe, "Microinvasive carcinoma of the cervix," Cancer, vol. 70, no. 8, pp. 2121-2128, 1992.

[12] C.-S. Tsai, C.-H. Lai, C.-C. Wang et al., "The prognostic factors for patients with early cervical cancer treated by radical hysterectomy and postoperative radiotherapy," Gynecologic Oncology, vol. 75, no. 3, pp. 328-333, 1999.

[13] F. Landoni, A. Maneo, G. Cormio et al., "Class II versus class III radical hysterectomy in stage IB-IIA cervical cancer: a prospective randomized study," Gynecologic Oncology, vol. 80, no. 1, pp. 3-12, 2001.

[14] S. Michalas, A. Rodolakis, Z. Voulgaris, G. Vlachos, N. Giannakoulis, and E. Diakomanolis, "Management of earlystage cervical carcinoma by modified (type II) radical hysterectomy," Gynecologic Oncology, vol. 85, no. 3, pp. 415-422, 2002.

[15] A. Maneo, F. Landoni, G. Cormio, A. Colombo, and C. Mangioni, "Radical hysterectomy for recurrent or persistent cervical cancer following radiation therapy," International Journal of Gynecological Cancer, vol. 9, no. 4, pp. 295-301, 1999.

[16] M. P. Boente, "Prognostic factors and long-term survival in endometrial adenocarcinoma with cervical involvement," Gynecologic Oncology, vol. 51, no. 3, pp. 316-322, 1993.

[17] A. Mariani, M. J. Webb, G. L. Keeney, G. Calori, and K. C. Podratz, "Role of wide/radical hysterectomy and pelvic lymph node dissection in endometrial cancer with cervical involvement," Gynecologic Oncology, vol. 83, no. 1, pp. 72-80, 2001.

[18] A. J. Mangram, T. C. Horan, M. L. Pearson, L. C. Silver, and W. R. Jarvis, "Guideline for prevention of surgical site infection, 1999. Hospital Infection Control Practices Advisory Committee," Infection Control and Hospital Epidemiology, vol. 20, no. 4, pp. 250-278, 1999.

[19] W. H. Geerts, D. Bergqvist, G. F. Pineo et al., "Prevention of venous thromboembolism: American College of Chest Physicians evidence-based clinical practice guidelines (8th edition)," Chest, vol. 133, no. 6, 2008.

[20] H.-B. Cai, H.-Z. Chen, Y.-F. Zhou, D.-M. Lie, and H.-Y. Hou, "Class II radical hysterectomy in low-risk ib squamous cell carcinoma of cervix: a safe and effective option," International Journal of Gynecological Cancer, vol. 19, no. 1, pp. 46-49, 2009.

[21] T. Manchana, N. Sirisabya, R. Lertkhachonsuk et al., "Long term complications after radical hysterectomy with pelvic lymphadenectomy," Journal of the Medical Association of Thailand, vol. 92, no. 4, pp. 451-456, 2009.

[22] I. S. Likic, S. Kadija, N. G. Ladjevic et al., "Analysis of urologic complications after radical hysterectomy," American Journal of Obstetrics and Gynecology, vol. 199, no. 6, pp. 644.e1-644.e3, 2008.

[23] D. P. Pikaart, R. W. Holloway, S. Ahmad et al., "Clinicalpathologic and morbidity analyses of types 2 and 3 abdominal radical hysterectomy for cervical cancer," Gynecologic Oncol$o g y$, vol. 107, no. 2, pp. 205-210, 2007.

[24] K. Wu, W. H. Zhang, R. Zhang, H. Li, P. Bai, and X. G. Li, "Analysis of postoperative complications of radical hysterectomy for 219 cervical cancer patients," Zhonghua Zhong Liu Za Zhi, vol. 28, no. 4, pp. 316-319, 2006.

[25] C. G. Zorlu, T. Aydoğdu, Y. Ergün, E. Kuşçu, Ö. Çobanoğlu, and S. Koçak, "Complications of radical hysterectomy: clinical experience of 115 early stage cervical cancers," Gynecologic and Obstetric Investigation, vol. 45, no. 2, pp. 137-139, 1998.

[26] F. S. Abrão, R. C. Breitbarg, A. T. Qliveira, and F. A. Vasconcelos, "Complications of surgical treatment of cervical carcinoma," Brazilian Journal of Medical and Biological Research, vol. 30, no. 1, pp. 29-33, 1997.

[27] M. A. Finan, S. DeCesare, J. V. Fiorica et al., "Radical hysterectomy for stage IB1 vs IB2 carcinoma of the cervix: does the new staging system predict morbidity and survival?" Gynecologic Oncology, vol. 62, no. 2, pp. 139-147, 1996.

[28] J. F. Magrina, M. A. Goodrich, A. L. Weaver, and K. C. Podratz, "Modified radical hysterectomy: morbidity and mortality," Gynecologic Oncology, vol. 59, no. 2, pp. 277-282, 1995.

[29] P. Benedetti-Panici, G. Scambia, G. Baiocchi, F. Maneschi, S. Greggi, and S. Mancuso, "Radical hysterectomy: a randomized study comparing two techniques for resection of the cardinal ligament," Gynecologic Oncology, vol. 50, no. 2, pp. 226-231, 1993.

[30] A. Ayhan, Z. S. Tuncer, and H. Yarali, "Complications of radical hysterectomy in women with early stage cervical cancer: clinical analysis of 270 cases," European Journal of Surgical Oncology, vol. 17, no. 5, pp. 492-494, 1991.

[31] E. Sartori, G. Tisi, F. Chiudinelli, B. La Face, R. Franzini, and S. Pecorelli, "Early stage cervical cancer: adjuvant treatment in negative lymph node cases," Gynecologic Oncology, vol. 107, no. 1, pp. S170-S174, 2007.

[32] C.-M. Ho, T.-Y. Chien, S.-H. Huang, C.-J. Wu, B.-Y. Shih, and S.-C. Chang, "Multivariate analysis of the prognostic factors and outcomes in early cervical cancer patients undergoing radical hysterectomy," Gynecologic Oncology, vol. 93, no. 2, pp. 458-464, 2004.

[33] A. Ayhan, R. A. Al, C. Baykal, E. Demirtas, A. Ayhan, and K. Yüce, "Prognostic factors in FIGO stage IB cervical cancer without lymph node metastasis and the role of adjuvant radiotherapy after radical hysterectomy," International Journal of Gynecological Cancer, vol. 14, no. 2, pp. 286-292, 2004.

[34] C.-H. Lai, J.-H. Hong, S. Hsueh et al., "Preoperative prognostic variables and the impact of postoperative adjuvant therapy on the outcomes of stage IB or II cervical carcinoma patients with or without pelvic lymph node metastases: an analysis of 891 cases," Cancer, vol. 85, no. 7, pp. 1537-1546, 1999.

[35] F.-S. Liu, M.-J. Hung, S.-F. Hwang, C.-H. Lu, Y.-M. Ke, and E. S.-C. Ho, "Management of pelvic lymphocysts by ultrasoundguided aspiration and minocycline sclerotherapy," Gynecologic and Obstetric Investigation, vol. 59, no. 3, pp. 130-133, 2005.

[36] A. Kavallaris, E. Abu Marar, D. Beyer, C. Banz, K. Diedrich, and C. Altgassen, "Management of symptomatic pelvic lymphocyst after radical pelvic or pelvic and paraaortic lymphadenectomy for cervical and endometrial cancer," Gynecological Surgery, vol. 6, no. 4, pp. 345-349, 2009. 


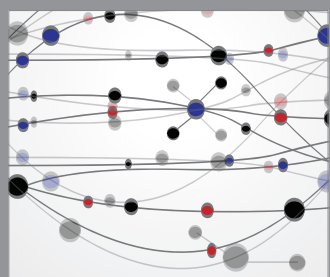

The Scientific World Journal
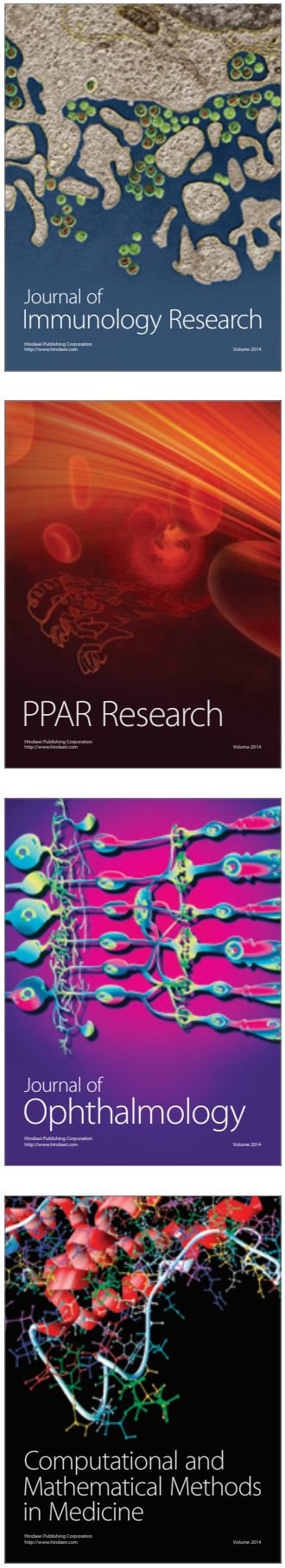

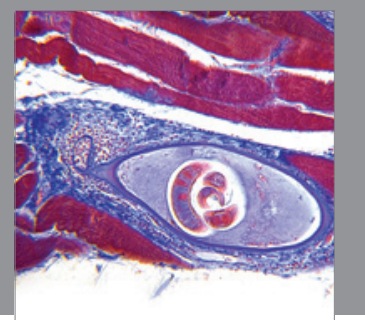

Gastroenterology

Research and Practice
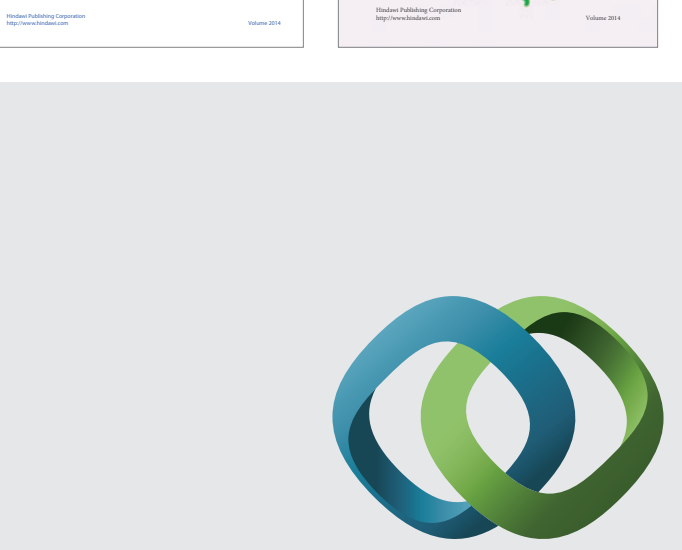

\section{Hindawi}

Submit your manuscripts at

http://www.hindawi.com
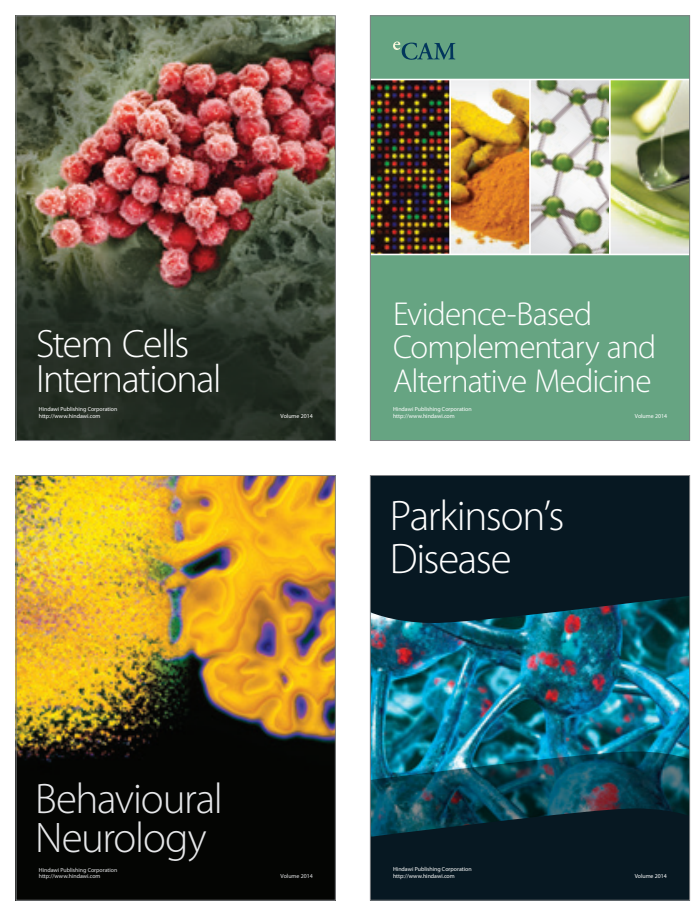

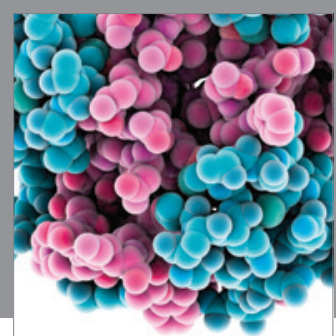

Journal of
Diabetes Research

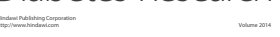

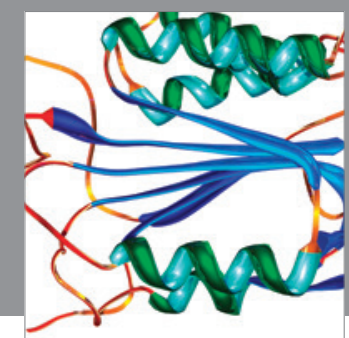

Disease Markers
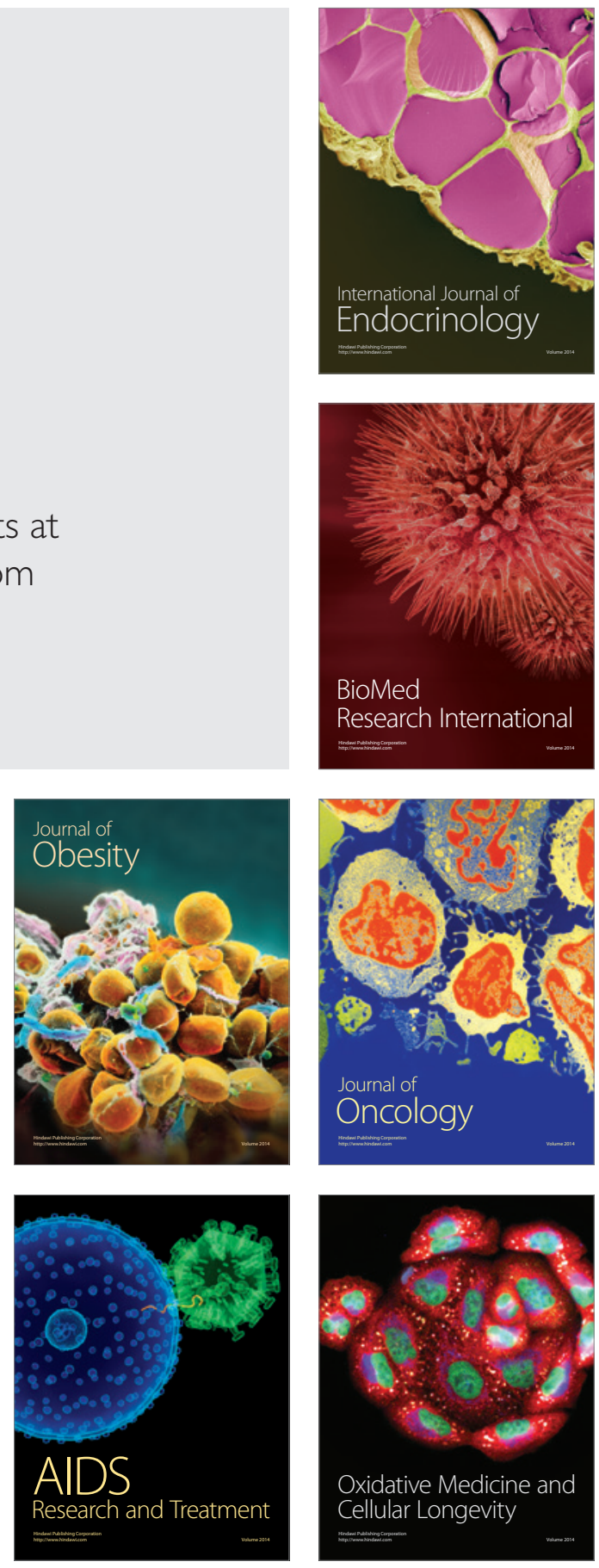